\title{
Radical-Radical Reactions, Pyrene Nucleation, and Incipient Soot Formation in Combustion
}

K. Olof Johansson, ${ }^{a}$ Tyler Dillstrom, ${ }^{\mathrm{b}}$ Paolo Elvati, ${ }^{\mathrm{b}}$ Matthew F. Campbell, ${ }^{\mathrm{a}}$ Paul E. Schrader, ${ }^{\mathrm{a}}$ Denisia

M. Popolan-Vaida, ${ }^{c, d}$ Nicole K. Richards-Henderson, ${ }^{c}$ Kevin R. Wilson, ${ }^{c}$ Angela Violi, ${ }^{\text {bee }}$ and Hope A. Michelsen $^{\mathrm{a}, *}$

${ }^{a}$ Combustion Research Facility, Sandia National Laboratories, Livermore, CA 94551, USA

${ }^{b}$ Department of Mechanical Engineering, University of Michigan, Ann Arbor, MI 48109, USA

${ }^{\mathrm{c} C h e m i c a l ~ S c i e n c e s ~ D i v i s i o n, ~ L a w r e n c e ~ B e r k e l e y ~ N a t i o n a l ~ L a b o r a t o r y, ~ B e r k e l e y, ~ C A ~ 94720, ~ U S A ~}$

${ }^{\mathrm{d}}$ Department of Chemistry, University of California, Berkeley, CA 94720, USA

${ }^{\mathrm{e}}$ Departments of Chemical Engineering, Biomedical Engineering, Macromolecular Science and Engineering, Biophysics Program, University of Michigan, Ann Arbor, MI 48109, USA

*To whom correspondence should be addressed:

Combustion Research Facility, Sandia National Laboratories, P. O. Box 969, MS 9055, Livermore, CA 94551, USA.

Tel.: +1 925294 2335; fax: +19252942276

E-mail address: hamiche@ @andia.gov

Colloquium: SOOT, NANOPARTICLES, PAH AND OTHER LARGE MOLECULES

Total length of paper using method 1: 6127 words 
Abstract 242

Introduction $\quad 647$

Methods 631

Results and Discussion 2657

Conclusion $\quad 192$

Acknowledgements $\quad 129$

37 References 682

5 Figures $(189+176+268+147+489) \quad 1189$

Fig. 1: $(64.0 \mathrm{~mm}+10) * 2.2 * 1+26$ words

Fig. 2: $(37.7 \mathrm{~mm}+10) * 2.2 * 1+66$ words

Fig. 3: $(76.9 \mathrm{~mm}+10) * 2.2 * 1+45$ words

Fig. 4: $(42.0 \mathrm{~mm}+10) * 2.2 * 1+33$ words

Fig. 5: $(78.1 \mathrm{~mm}+10) * 2.2 * 2+58$ words

Total (excluding abstract) 6127 


\section{Abstract:}

We present a combined experimental and probabilistic simulation study of soot-precursor molecules. The experiments were conducted using aerosol mass spectrometry coupled with tunable vacuum ultraviolet radiation from the Advanced Light Source at Lawrence Berkeley National Laboratory. Mass spectra and photoionization efficiency (PIE) curves of incipient-soot particle constituents were measured at different heights in a premixed flat flame and in a counter-flow diffusion flame fueled by ethylene and oxygen. The PIE curves at the pyrene mass from these flames were compared with reference PIE scans recorded for pyrene. The results demonstrate that pyrene is not a major component of incipient soot, which is in agreement with the simulations. Species with mass $202 \mathrm{u}$ only have a high prevalence in incipient soot particles drawn from the premixed flame, but hydrocarbon species with sizes in the range 200-400 u are important to incipient-soot formation in both flames. The simulations predict that some species form through combination reactions involving relatively large radicals and bypass traditional molecular-growth pathways through addition of small hydrocarbon species. The experimental results support this prediction; they demonstrate that these species have higher relative abundances in particles formed close to the fuel outlet than smaller, lighter molecular species and indicate that these species are important to early formation of incipient soot precursors. The results also imply that a leading role in incipient-soot precursor formation is played by species with lower thermal stability than the even-carbon numbered, unsubstituted polycyclic aromatic hydrocarbons known as "stabilomers".

Keywords: Incipient Soot; Ethylene Flame; PAH; Radical Reactions; Pyrene 


\section{Introduction}

Combustion-generated soot particles have significant adverse effects on climate [1-6], air quality [3], and human health [3,7-10]. Despite the need to mitigate soot-particulate emissions, however, many of the factors that control soot formation are poorly understood. A critical, but poorly understood, step in soot-formation chemistry is the transition from gas-phase species to particles [11]. Nucleation of polycyclic aromatic hydrocarbons (PAHs) is thought to play a central role in particle inception, which is supported by experimental evidence for PAH stacking in soot; see, for example, the study by Baquet et al. [12] and the review by Wang [13].

Homogeneous nucleation could be the step responsible for formation of the critical nuclei, but there is debate about the molecular size required for two PAH molecules to be physically bound long enough to nucleate a particle. Miller [14] calculated that sticking PAH collisions are only important for PAHs with masses larger than $800 \mathrm{u}$. Schuetz and Frenklach [15] calculated lifetimes for pyrene dimers, however, and found that they are stabilized by internal rotational and vibrational motion of the cluster and may survive long enough for subsequent growth to occur. Such a kinetically controlled process requires reversibility, and Eaves et al. [16] recently presented a nucleation study that accounts for reversibility. Nucleation was modeled to result from collisions mainly with benzo[a]pyrene, a species one aromatic ring larger than pyrene. These results are supported by those of Herdman and Miller [17] who calculated that the binding energies of heterodimers with reduced masses as low as $83 \mathrm{u}$ can survive at $1500 \mathrm{~K}$.

Sabbah et al. [18] presented evidence discounting the importance of pyrene dimerization for soot formation in flames. Their experimental results indicated that the pyrene partial pressure required for $10 \%$ conversion to the pyrene dimer at $1500 \mathrm{~K}$ is in excess of $40 \mathrm{bar}$, which far exceeds the pressure of most flames. They concluded that the equilibrium of the dimerization favors dissociation at high 
temperatures and that chemical growth to PAHs much larger than pyrene is required before homogeneous condensation can lead to significant soot formation under many combustion conditions. Kraft and co-workers [19] came to the same conclusion in their calculations of PAH clustering for particle inception. However, these two studies focused on pyrene homodimers and equilibrium considerations. Further theoretical evidence against pyrene nucleation was presented by Elvati and Violi [20]. They pointed out that the presence of aliphatic side chains on condensed-ring structures can strengthen interactions between colliding molecules, allowing them to remain in close proximity long enough for reactions to occur. In addition, Lowe et al. [21] showed that the main parameter determining dimer stability in heterodimers is the size of the smallest monomer, and pyrene needs to stick with a hydrocarbon the size of ovalene to yield a stable complex at $\sim 1000 \mathrm{~K}$. Despite these indications against pyrene nucleation, it is often used as a proxy for soot formation in combustion [22-25].

There is a severe paucity of experimental data that definitively either support or eliminate nucleation of pyrene or similar-sized PAHs under atmospheric flame conditions. Many studies of incipient particle composition rely on aerosol mass spectrometry. For large hydrocarbon species, however, molecular structures cannot be identified by mass alone. Mass-resolved studies of soot constituents are often interpreted assuming observed masses are stabilomers [26-28], a class of species containing the most thermodynamically stable hydrocarbons, including pyrene [29]. These studies typically suggest pyrene and similar-sized PAHs to be important soot precursors because of the high intensities normally found in the mass range $200 \mathrm{u}-400 \mathrm{u}$. The study described here was designed to (1) determine whether pyrene is the dominant species observed at mass $202 \mathrm{u}$ in incipient soot particles extracted from flames, (2) identify species at the heavier masses of $226 \mathrm{u}, 266 \mathrm{u}$, and $278 \mathrm{u}$, which appear to be important to the first particles formed, and (3) determine formation mechanisms for these species. 


\section{Methods}

\subsection{Experimental Approach}

We performed experiments using a time-of-flight aerosol mass spectrometer (AMS) coupled with synchrotron vacuum-ultraviolet (VUV) radiation for photoionization. VUV photoionization limits fragmentation compared to other ionization approaches, e.g., electron impact ionization or nanosecond laser photoionization, and enables improved detection of parent species that are prone to fragmentation, such as many non-aromatic hydrocarbons. Sample gas and particles were extracted either from an atmospheric pressure premixed $\mathrm{C}_{2} \mathrm{H}_{4} / \mathrm{O}_{2}$ flame with an equivalence ratio of 2.09 or from an atmospheric pressure $\mathrm{C}_{2} \mathrm{H}_{4} / \mathrm{O}_{2}$ counter-flow diffusion flame.

The premixed burner was a modified McKenna design with a 38.1-mm porous bronze plug through which we flowed a mixture of ethylene $\left(\mathrm{C}_{2} \mathrm{H}_{4}\right)$, oxygen $\left(\mathrm{O}_{2}\right)$, and nitrogen $\left(\mathrm{N}_{2}\right)$. The central plug was surrounded by a bronze porous ring for flowing a shroud gas of $\mathrm{N}_{2}$. A water-cooled stainless steel cylinder was mounted $13.3 \mathrm{~mm}$ above the porous plug to stabilize the flame, and the cooling water was maintained at $288 \mathrm{~K}$. The low thermal conductivity of stainless steel led to a stabilization-plate surface temperature of $\sim 375 \mathrm{~K}$. The gas-flow rates through the central plug were: 0.67 liters per minute (lpm) $\mathrm{C}_{2} \mathrm{H}_{4}$ mixed with $0.96 \mathrm{lpm} \mathrm{O}_{2}$ and $3.62 \mathrm{lpm} \mathrm{N}_{2}$. All gas-flow rates were referenced to $273 \mathrm{~K}$ and $1.01325 \times 10^{5} \mathrm{~Pa}$. The gas-flow rate through the outer ring was $19 \mathrm{lpm} \mathrm{N_{2 }}$.

The counter-flow diffusion burner consisted of two vertically mounted flow tubes $(12.7 \mathrm{~mm}$ inner diameter) facing one another and separated by $12 \mathrm{~mm}$. The bottom tube flowed a mixture of $\mathrm{C}_{2} \mathrm{H}_{4}$ and $\operatorname{argon}(\mathrm{Ar})$, and the top tube flowed $\mathrm{O}_{2}$ and Ar. The flow rates were $0.23 \mathrm{lpm} \mathrm{C}_{2} \mathrm{H}_{4}$ and $1.10 \mathrm{lpm} \mathrm{Ar}$ for the bottom tube and $0.25 \mathrm{lpm} \mathrm{O}_{2}$ diluted in $1.20 \mathrm{lpm} \mathrm{Ar}$ for the top tube. Outer flow tubes with an inner 
diameter of $18.364 \mathrm{~mm}$ surrounded these tubes for flowing a shroud gas of Ar. The flow rates were 2.30 lpm for the lower tube and $3.00 \mathrm{lpm}$ for the upper tube.

Combustion-generated nanoparticles were sampled along the vertical centerline of the flames using a quartz probe with a tapered tip. The probe assembly was fixed and the burner assembly was translated vertically to sample at different flame heights. The sample was guided through an aerodynamic lens system [30,31] to produce a particle beam. Gas-phase species are rapidly suppressed by several orders of magnitude compared to particles downstream of the aerodynamic lens system. We used a target heated to $\sim 570 \mathrm{~K}$ to vaporize species in the ionization region where the pressure was $\sim 7 \times 10^{-7}$ Torr. Molecules that vaporized from the target were photoionized using tunable VUV radiation, generated at the Advanced Light Source synchrotron (ALS) at Lawrence Berkeley National Laboratory (LBNL). The molecular ions produced were pulse-extracted into a time-of-flight mass spectrometer at a rate of 15 $\mathrm{kHz}$, and mass spectra were recorded using a multichannel scaler.

\subsection{Numerical Approach}

SNAPS [32] is a stochastic chemical kinetics simulator designed to predict PAH and oxygenated-PAH growth in flames. SNAPS models the formation and growth/decomposition of PAHs starting from an initial "seed" molecule, reconstructing the probabilities of forming an indefinite number of species throughout the flame. The SNAPS code includes carbon addition through reactions of methyl, methane, acetylene, vinyl, ethylene, ethane, ethyl, propargyl, butatriene, cyclopentadienyl, cyclopentadiene, phenyl, and benzene. Oxygen chemistry is included through reactions with $\mathrm{O}, \mathrm{O}_{2}, \mathrm{OH}, \mathrm{HO}_{2}, \mathrm{H}_{2} \mathrm{O}_{2}, \mathrm{H}_{2} \mathrm{O}$, $\mathrm{CO}$, and $\mathrm{CO}_{2}$, and all reactions are fully reversible. SNAPS has been validated against experimental data from premixed and diffusion-controlled combustion [32-34]. The gas-phase environment (needed as input for SNAPS) was obtained using the PREMIX program in CHEMKIN [35], using the deterministic 
kinetic mechanism of Appel-Bockhorn-Frenklach [23]. We simulated the evolution of benzene or toluene (ratio 1:1) molecules over 20,000 realizations starting from the premixed burner surface. See Ref. [32] for further details about the SNAPS code and methodology.

\section{Results and Discussion}

Figure 1 shows aerosol mass spectra recorded at a distance from the fuel outlet (DFFO) of $3.4 \mathrm{~mm}$ in the premixed flame and a DFFO of $3.0 \mathrm{~mm}$ in the counter-flow flame. The signal was weak for smaller DFFOs in the two flames. The photon energy was about $9.6 \mathrm{eV}$. Mass spectra recorded in the premixed flame extend to $\sim 500 \mathrm{u}$ and those recorded in the counter-flow diffusion flame extend to $\sim 600 \mathrm{u}$, but the mass-axes have been truncated at $425 \mathrm{u}$ in order not to congest the graph. We assume singly ionized molecules and thus refer to the mass instead of the mass-to-charge-ratio. Figure 1 shows that the peak at $202 \mathrm{u}$ is the second strongest peak after the one at $226 \mathrm{u}$ in the premixed flame. The intensity ratio between these two peaks approaches unity at larger DFFOs, and the peak at $202 \mathrm{u}$ eventually becomes the strongest one. The peak at $202 \mathrm{u}$ is relatively weak in the counter-flow flame and makes up less than $0.4 \%$ of the total signal above $201.7 \mathrm{u}$, indicating that structures at $202 \mathrm{u}$ constitute a negligible molecular ensemble for particle formation in this flame. Hence, pyrene contribution to incipient soot particles could only be important in the premixed flame. In general, the signal stems from heavier species in the counter-flow flame than in the premixed flame. The mass spectra shown in Fig. 1 have not been corrected for photoionization efficiencies or the vaporization efficiencies of different species at $\sim 570 \mathrm{~K}$, both of which influence the mass-peak intensities; the peaks thus do not provide quantitative species abundances. Nevertheless, nearby mass peaks tend to have similar vaporization efficiencies, and species lighter than $\sim 300 \mathrm{u}$ are fully vaporized. In addition, if the majority of the observed peaks stem from similar aromatic structures, such as most of the stabilomers [29], the photoionization cross sections 
will be comparable, and the peak intensities of nearby mass peaks in Fig. 1 should provide indications of the relative molecular abundances.

One way of determining if pyrene dominates the signal contribution at $202 \mathrm{u}$ in the premixed flame is to study the ion-signal response as the ionizing-photon energy is tuned and compare the result to measurements of pure pyrene. If pyrene is the dominant structure found in incipient soot particles at 202 $\mathrm{u}$, photoionization-efficiency (PIE) curves recorded for the peak at $202 \mathrm{u}$ from incipient soot sampled from the flame should closely resemble the curve recorded for pyrene introduced into the aerosol mass spectrometer.

We measured PIE curves at DFFO = $3.4 \mathrm{~mm}, 5.4 \mathrm{~mm}$, and $9.4 \mathrm{~mm}$ in the premixed flame, and there was no observable difference in shape between the PIEs recorded at the different flame heights, although the total signal intensity at $202 \mathrm{u}$ varied greatly with DFFO. The results are displayed in Fig. 2 . The hatched area shows the bounds of four PIE measurements, one at DFFO $=3.4 \mathrm{~mm}$, two at DFFO $=5.4 \mathrm{~mm}$, and one at $\mathrm{DFFO}=9.4 \mathrm{~mm}$. The PIE-curve shape from pyrene was recorded by coating $\mathrm{NaCl}$ particles as they flowed through pyrene vapor. The particles were sampled through the aerodynamic lens system and focused onto the heated target in the ionization region in exactly the same way the particles sampled from the flame were measured. The bounds of two separate pyrene PIE curves are shown by the blue ( gray in grayscale) curve in Fig. 2. This curve demonstrates excellent agreement with the shape of the pyrene photoionization-cross section curve measured by Verstraete et al. [36] (black line in Fig. 2). We convolved their curve with our photon-energy distribution function and added a small intensity offset. The offset is justified because our photon-energy distribution sits on a wide plateau, and a small flux of photons that are significantly more energetic than the ones at the center of the distribution reach the ionization region. These high-energy photons generate a nearly constant signal offset. The pyrene PIE 
curve lies slightly below the pyrene photoionization cross-section curve at low and high photon energies because the photon flux decreases at the edges of the scan limits, and we have not corrected for this effect.

Figure 2. The red (dark gray in grayscale) curve shows the lower and upper bounds of four separate PIE scans for the mass peak at $202 \mathrm{u}$ in the flame. The light blue (light gray in grayscale) curve displays the bounds for two PIE scans performed on pyrene. Also shown is the curve shape of the pyrene photoionization cross section $\left(\sigma_{\mathrm{PI}}\right)$ obtained from Verstraete et al. [36]. See text for details.

Figure 2 shows that the PIE curves recorded in the flame differ substantially from the PIE curve of pyrene. This result does not prove the absence of pyrene in incipient soot extracted from the premixed flame. However, it demonstrates that species other than pyrene contribute significantly to the signal at $202 \mathrm{u}$. The large number of potentially important $\mathrm{C}_{16} \mathrm{H}_{10}$ isomers in the flame makes it impossible to parse out reliable information about isomeric contributions. Photoionization-cross section curves are rare for $\mathrm{C}_{16} \mathrm{H}_{10}$ isomers and appear to be readily available only for pyrene. Even if the photoionization cross sections had been known for all isomers, however, it is highly unlikely that these curves would differ enough to constitute a robust basis set that could provide reliable fits to experimental data. This remark is supported by the featureless curve recorded for pure pyrene (Fig. 2). In addition, the energy resolution of the beamline end station is relatively low and the ionization threshold of the soot-signal in Fig. 2 lies below the lowest obtainable photon energy, meaning that the ionization threshold cannot be determined. Nevertheless, the results suggest that pyrene does not contribute substantially to the incipient soot composition under the present flame conditions. In addition, Fig. 2 demonstrates that the species that contribute to the peak at $202 \mathrm{u}$ close to and far from the burner have the same or similar PIE curves, suggesting that they are the same or very similar species throughout the flame. 
The broad feature seen for the flame PIE curves between 8 and $9.5 \mathrm{eV}$ in Fig. 2 is not unique to the premixed flame. This feature also appears in PIE curves from different DFFOs in the counter-flow diffusion flame and has been reported previously in PIE curves from an acetylene $\left(\mathrm{C}_{2} \mathrm{H}_{2}\right)$ counter-flow diffusion flame [34]. The intensity of the peak at $202 \mathrm{u}$ is relatively weak in the mass spectra from both the ethylene counter-flow flame (shown in Fig. 1b) and the acetylene counter-flow flame (shown previously [34]). Pyrene thus appears to be a negligible contributor to the composition of incipient soot extracted from the counter-flow diffusion flames. For the acetylene counter-flow flame, simulations using SNAPS $[32,34]$ suggested that pyrene was not one of the five most likely soot-precursor species containing 16 carbon atoms [34]. The main species with 16 carbon atoms predicted by the simulations was 3-ethynylcyclopenta[fg]acenaphthylene (A.III in Fig. 3 with two fewer hydrogen atoms).

SNAPS simulations of the premixed ethylene flame under study reveal that the plurality of species at $202 \mathrm{u}$ is a derivative of anthracene, not pyrene (Fig. 3 left column). At a DFFO of $3.4 \mathrm{~mm}$, pyrene is only the fifth most likely (12\%) isomer of 202-u species, and $86 \%$ of $202-\mathrm{u}$ species contain at least one 5-membered ring and are products of the growth trajectories of acenaphthylene $\left(\mathrm{C}_{12} \mathrm{H}_{8}\right)$. This result can be explained by analyzing the most common growth pathways observed with SNAPS that lead to species with mass 202 u. Starting from benzene, the initial growth pathways strongly favor the formation of a second six-membered ring (naphthalene) rather than a five-membered ring (indene) because the former requires the adsorption of two C2 molecules (e.g., acetylene) on neighboring carbons while the latter requires the adsorption of either one C3 molecule (e.g., propargyl) or one C2 molecule and one methyl group. Because of the high concentration of acetylene relative to propargyl or methyl in the gas phase, bimolecular reactions involving acetylene are significantly more frequent: the probability of reactions that involve acetylene during PAH growth is about $11.3 \%$, while for propargyl and methyl 
reactions the probability decreases to $0.008 \%$ and $0.04 \%$, respectively. For this reason, the vast majority of nascent PAHs are naphthalene molecules, which then grow to form acenaphthylene rather than anthracene or phenanthrene because the former simply requires the adsorption of one acetylene to one of four zigzag sites of the molecule and a fast unimolecular ring closure, while anthracene or phenanthrene require the addition of two acetylene molecules on neighboring carbons. The result is that formation of acenaphthylene is about 5 times more likely in the lower portion of the flame than formation of phenanthrene. Hence, the pathways leading to pyrene formation are restricted, explaining the low concentration of pyrene relative to 202-u structures containing at least one 5-member ring.

The precursors of species A.I and A.II (Fig. 3) have similar concentrations. Phenanthrene, however, has two main pathways orchestrating further molecular growth, i.e., addition of one acetylene on the bay site (followed by a ring closure) to form pyrene or addition of one acetylene on the zigzag sites (followed by a ring closure) to form compound A.II. Hence, the fraction of phenanthrene molecules that grows to 202 $\mathrm{u}$ is divided between compounds A.II and A.V, which ensures a larger abundance of A.I than A.II or A.V.

Although pyrene appears to be insignificant among the species found in incipient soot particles, structure B.I in Fig. 3 indicates that it may play a role for the continued mass growth of gas-phase species in the flames. Structure B.I, which is the most commonly predicted structure at $226 \mathrm{u}$, can be formed through acetylene addition to pyrene followed by ring closure, or via acetylene addition to the bay site of structure A.II followed by ring closure. Addition of a second acetylene molecule would generate a structure at $250 \mathrm{u}$, which is also a strong peak in the mass spectrum recorded at a DFFO of $3.4 \mathrm{~mm}$ in the premixed flame (Fig. 1a). Contrary to the mass spectrum recorded in the premixed flame, the mass spectrum recorded in the counter-flow flame (Fig. 1b) has higher intensity at $252 \mathrm{u}$ than at 250 
$\mathrm{u}$, which may suggest different formation pathways in the two flames for species containing 20 carbon atoms.

Siegmann et al. [37] found that species at $252 \mathrm{u}$ and $350 \mathrm{u}$ formed more rapidly than other species of similar molecular weights in laminar methane diffusion flames. They proposed a reactive dimerization mechanism in which stable PAH molecules such as naphthalene and anthracene lined up and dimerized. The species at $350 \mathrm{u}$ appears to grow more rapidly than several lighter ones, including the species at 202 $\mathrm{u}$ and $226 \mathrm{u}$ in the counter-flow flame under study. The signal at $252 \mathrm{u}$ shows a similar but weaker trend. We have previously shown that the species at $266 \mathrm{u}$ and $278 \mathrm{u}$ grow ahead of lighter structures in an acetylene counter-flow diffusion flame [34], and the same trend is observed in the two flames under study.

Figure 4 displays normalized signal profiles, i.e., the mass-peak intensity as a function of the DFFO, for the peaks at $202 \mathrm{u}, 226 \mathrm{u}, 266 \mathrm{u}$, and $278 \mathrm{u}$ recorded in the premixed flame. The peaks at $202 \mathrm{u}$ and 226 $\mathrm{u}$ were found to be the two strongest peaks in Fig. 1, but their relative importance at small DFFOs is smaller than the relative importance of the species at $266 \mathrm{u}$ and $278 \mathrm{u}$, as seen in Fig. 4 . The signals at $266 \mathrm{u}$ and $278 \mathrm{u}$ rise at smaller DFFOs than the signals at $202 \mathrm{u}$ and $226 \mathrm{u}$, and, therefore, have larger relative abundancies than the species at $202 \mathrm{u}$ and $226 \mathrm{u}$ among the very first soot particles that are large enough to be focused by the aerodynamic lens system. The profile at $226 \mathrm{u}$ has a steeper rise than the one at $202 \mathrm{u}$ once these two profiles start rising, which is manifested in a stronger signal at $226 \mathrm{u}$ compared to $202 \mathrm{u}$ in Fig. 1. The delayed rise of the profile at $202 \mathrm{u}$ as a function of DFFO is particularly pronounced in the ethylene counter-flow flame where the absolute intensity of this peak is relatively weak throughout the flame and the intensity of the signal at $266 \mathrm{u}$ and $278 \mathrm{u}$ is relatively high for small DFFOs. 
In order to explain these experimental results, we analyzed the species with masses $202 \mathrm{u}, 226 \mathrm{u}, 266 \mathrm{u}$, and $278 \mathrm{u}$ produced by SNAPS at 2.4 and $3.4 \mathrm{~mm}$ DFFO in the premixed flame. As expected based on the experimental results, at a DFFO of $2.4 \mathrm{~mm}$ the probability of forming these masses was predicted to be small ( $<0.1 \%$ of SNAPS trajectories), and species with mass $266 \mathrm{u}$ or $278 \mathrm{u}$ were more frequently formed than the ones with masses $202 \mathrm{u}$ and $226 \mathrm{u}$. The small number of relevant trajectories, however, makes it difficult to draw clear conclusions. The initial analysis of the structures at these four masses at a DFFO of $3.4 \mathrm{~mm}$ showed a greater abundance of species with masses $202 \mathrm{u}(0.60 \%$ of total PAH species) and $226 \mathrm{u}(0.46 \%)$ than those with masses $266 \mathrm{u}(0.19 \%)$ and $278 \mathrm{u}(0.02 \%)$.

A large number of smaller PAH radicals (the most common are shown in Fig. 5) were also predicted, and, if combined, they could change the amounts of the species at the four masses $202 \mathrm{u}, 226 \mathrm{u}, 266 \mathrm{u}$, and $278 \mathrm{u}$. We estimated the importance of combination pathways of these PAH radicals by considering the frequency of collision of the various radicals and assuming a collision efficiency of 0.85 . A negligible amount of masses 202 and $226 \mathrm{u}$ are formed from PAH radical-radical combination reactions, while significant amounts of compounds with masses 266 and $278 \mathrm{u}$ are formed, increasing the amount of mass $266 \mathrm{u}$ by $35 \%$ and the amount of mass $278 \mathrm{u}$ by over $1133 \%$ at $3.4 \mathrm{~mm}$. These computational results indicate that masses $266 \mathrm{u}$ and $278 \mathrm{u}$ could have comparable concentrations to some smaller masses, such as $202 \mathrm{u}$, at small flame heights. Moreover, in the case of $278 \mathrm{u}$, about $93 \%$ of the species are molecules that skip traditional HACA pathways and form via PAH radical-radical combination. For species at $266 \mathrm{u}$, about $26 \%$ have undergone PAH radical-radical combination. The importance of the PAH radical-radical reaction pathways depends on the distribution of radical species at a given point in the flame; frequent combinations will be effective at changing the mass frequency distribution. As the concentration of PAH radicals is comparatively small, however, the most relevant effects are observed 
when the small collision frequency is offset by a substantial increase in mass. For these reasons, the "non-sequential" growth via PAH radical-radical combination grows in importance at higher DFFOs. It is, however, difficult to experimentally confirm non-sequential growth at large DFFOs, because of significant signal from lighter species, such as those at $202 \mathrm{u}$ and $226 \mathrm{u}$, high in the flame. Nevertheless, the presence of non-sequential growth at small DFFOs shows that fast soot-precursor growth pathways play a role low in the flame. It is conceivable that these and similar pathways remain open also higher in the flame, as suggested by SNAPS.

Figure 4 also shows that the signal at 202 u continues to increase with increasing DFFO in the premixed flame whereas the signals for the other three masses all reach a maximum below $6 \mathrm{~mm}$. We observe the same trend in the ethylene counter-flow flame, where the profile at $202 \mathrm{u}$ rises nearly monotonically, and the three other profiles reach maxima midway through the flame. This result suggests that the production of the species with a mass of $202 \mathrm{u}$ sampled from the two flames increases with increasing DFFO. One explanation for nearly monotonic signal increase at $202 \mathrm{u}$ with increasing DFFO could be that the surrounding molecules and particles grow larger with increasing DFFO. Collision with a larger species could enhance the chances for a relatively light and volatile molecule, e.g., $202 \mathrm{u}$, to bind to its larger collision partner [17] and remain condensed all the way to the ionization region of the AMS. Alternatively, the species at $202 \mathrm{u}$ may undergo production on the surfaces of soot particles at larger DFFOs.

\section{Conclusions}

These results show that pyrene and, by extension, its dimerization have limited importance to incipient soot production, except for potentially orchestrating further mass growth in the gas phase. Flame-PIE curves further demonstrate that pyrene is unlikely to be a major contributor to the mass peak at $202 \mathrm{u}$, a 
result that is in agreement with probabilistic simulations of soot-precursor species of this mass. If pyrene is a significant component in the gas-phase composition of the flame, it is not readily partitioned into particles, but the simulations suggest that it may propagate further gas-phase growth. Most of the soot precursor structures reported by SNAPS at $202 \mathrm{u}$ and $226 \mathrm{u}$ contain five-membered rings as opposed to only six-membered rings.

Both the experiments and the simulations show that larger species can grow ahead of lighter ones at low flame heights and generate heavy structures that might precipitate nucleation and particle-mass growth at early stages. The simulations suggest that the non-sequential growth happens through combination of moderately sized radicals, thereby bypassing traditional chemical-growth paths that advance through addition of small non-saturated hydrocarbons. Thus, PAH radical combination reactions provide fast routes for mass growth.

\section{Acknowledgements}

This work was funded by the U.S. Department of Energy (DOE), Office of Basic Energy Sciences (BES). AV, TD, and KOJ were supported under the Single Investigator Small Group Research (SISGR), Grant no. DE-SC0002619. MFC, PES, and HAM and experimental expenses, including burner design and construction, were supported by DOE, BES, the Division of Chemical Sciences, Geosciences, and Biosciences. Measurements were performed at the LBNL ALS. The ALS, NKRH, and KRW were supported by the Director, DOE BES, under Contract no. DE-AC02-05CH11231. DMPV is grateful to the Alexander von Humboldt Foundation for a Feodor Lynen fellowship. Sandia National Laboratories is a multi-program laboratory managed and operated by Sandia Corporation, a wholly owned subsidiary of Lockheed Martin Company, for the DOE's National Nuclear Security Administration under Contract no. DE-AC04-94-AL85000. 


\section{References}

[1] IPCC, Climate Change 2013: The Physical Science Basis. Working Group I Contribution to the Fifth Assessment Report of the Intergovernmental Panel on Climate Change, Cambridge University Press, Cambridge, UK and New York, NY, 2013.

[2] T.C. Bond, S.J. Doherty, D.W. Fahey, P.M. Forster, T. Berntsen, B.J. DeAngelo, M.G. Flanner, S. Ghan, B. Kärcher, D. Koch, S. Kinne, Y. Kondo, P.K. Quinn, M.C. Sarofim, M.G. Schultz, M. Schulz, C. Venkataraman, H. Zhang, S. Zhang, N. Bellouin, S.K. Guttikunda, P.K. Hopke, M.Z. Jacobson, J.W. Kaiser, Z. Klimont, U. Lohmann, J.P. Schwarz, D. Shindell, T. Storelvmo, S.G. Warren, C.S. Zender, Journal of Geophysical Research 118 (11) (2013) 5380-5552.

[3] E.J. Highwood, R.P. Kinnersley, Environ. Int. 32 (2006) 560-566.

[4] J. Hansen, L. Nazarenko, Proceedings of the National Academy of Sciences of the United States of America 101 (2) (2004) 423-428.

[5] S. Menon, J. Hansen, L. Nazarenko, Y. Luo, Science 297 (5590) (2002) 2250-2253.

[6] Ö. Gustafsson, M. Kruså, Z. Zencak, R.J. Sheesley, L. Granat, E. Engström, P. Praveen, P. Rao, C. Leck, H. Rodhe, Science 323 (5913) (2009) 495-498.

[7] H. Horvath, Journal of Environmental Radioactivity 51 (2000) 5-25.

[8] J.S. Lighty, J.M. Veranth, A.F. Sarofim, Journal of the Air \& Waste Management Association 50 (9) (2000) 1565-1618.

[9] N.A.H. Janssen, G. Hoek, M. Simic-Lawson, P. Fischer, L. van Bree, H. ten Brink, M. Keuken, R.W. Atkinson, H.R. Anderson, B. Brunekreef, F.R. Cassee, Environ. Health Perspect. 119 (12) (2011) 16911699.

[10] A. Sydbom, A. Blomberg, S. Parnia, N. Stenfors, T. Sandström, S. Dahlen, European Respiratory Journal 17 (4) (2001) 733-746.

[11] M. Frenklach, Phys. Chem. Chem. Phys. 4 (11) (2002) 2028-2037.

[12] T.G. Baquet, H.H. Grotheer, M. Aigner, Rapid Commun. Mass Spectrom. 21 (24) (2007) 4060-4064.

[13] H. Wang, Proc. Combust. Inst. 33 (1) (2011) 41-67.

[14] J.H. Miller, The kinetics of polynuclear aromatic hydrocarbon agglomeration in flames, Symp. Int. Combust. Elsevier, 1991, p. 91-98.

[15] C.A. Schuetz, M. Frenklach, Proc. Combust. Inst. 29 (2) (2002) 2307-2314.

[16] N. Eaves, S. Dworkin, M. Thomson, Proc. Combust. Inst. 35 (2) (2015) 1787-1794.

[17] J.D. Herdman, J.H. Miller, J. Phys. Chem. A 112 (28) (2008) 6249-6256.

[18] H. Sabbah, L. Biennier, S.J. Klippenstein, I.R. Sims, B.R. Rowe, The Journal of Physical Chemistry Letters 1 (19) (2010) 2962-2967.

[19] T.S. Totton, A.J. Misquitta, M. Kraft, Phys. Chem. Chem. Phys. 14 (12) (2012) 4081-4094.

[20] P. Elvati, A. Violi, Proc. Combust. Inst. 34 (1) (2013) 1837-1843.

[21] J.S. Lowe, J.Y. Lai, P. Elvati, A. Violi, Proc. Combust. Inst. 35 (2) (2015) 1827-1832.

[22] A. Raj, M. Sander, V. Janardhanan, M. Kraft, Combust. Flame 157 (3) (2010) 523-534.

[23] J. Appel, H. Bockhorn, M. Frenklach, Combust. Flame 121 (1) (2000) 122-136.

[24] X.-S. Bai, M. Balthasar, F. Mauss, L. Fuchs, Detailed soot modeling in turbulent jet diffusion flames, Symp. Int. Combust. Elsevier, 1998, p. 1623-1630.

[25] N.A. Eaves, A. Veshkini, C. Riese, Q. Zhang, S.B. Dworkin, M.J. Thomson, Combust. Flame 159 (10) (2012) 3179-3190.

[26] A. Faccinetto, P. Desgroux, M. Ziskind, E. Therssen, C. Focsa, Combust. Flame 158 (2) (2011) 227-239.

[27] R. Dobbins, R.A. Fletcher, H.-C. Chang, Combust. Flame 115 (3) (1998) 285-298.

[28] M. Matti Maricq, Combust. Flame 158 (1) (2011) 105-116.

[29] S.E. Stein, A. Fahr, J. Phys. Chem. 89 (17) (1985) 3714-3725. 
[30] X. Zhang, K.A. Smith, D.R. Worsnop, J.L. Jimenez, J.T. Jayne, C.E. Kolb, J. Morris, P. Davidovits, Aerosol Sci. Technol. 38 (6) (2004) 619-638.

[31] J.M. Headrick, P.E. Schrader, H.A. Michelsen, J. Aerosol Sci. 58 (2013) 158-170.

[32] J.Y. Lai, P. Elvati, A. Violi, Phys. Chem. Chem. Phys. 16 (17) (2014) 7969-7979.

[33] K.O. Johansson, T. Dillstrom, M. Monti, F.E. Gabaly, M.F. Campbell, P.E. Schrader, D.M. Popolan-Vaida, N.K. Richards-Henderson, K.R. Wilson, A. Violi, H.A. Michelsen, Submitted to Proc. Natl. Acad. Sci. U.S.A.

[34] K. Johansson, J. Lai, S. Skeen, D. Popolan-Vaida, K. Wilson, N. Hansen, A. Violi, H. Michelsen, Proc. Combust. Inst. 35 (2) (2015) 1819-1826.

[35] R. Kee, F. Rupley, J. Miller, M. Coltrin, J. Grcar, E. Meeks, H. Moffat, A. Lutz, G. Dixon-Lewis, M. Smooke, Reaction Design, San Diego, CA (2006).

[36] L. Verstraete, A. Leger, L. d'Hendecourt, D. Defourneau, O. Dutuit, Astron. Astrophys. 237 (1990) 436444.

[37] K. Siegmann, H. Hepp, K. Sattler, Combust. Sci. Technol. 109 (1-6) (1995) 165-181. 


\section{Figure captions}

Figure 1. Aerosol mass spectra recorded at (a) DFFO $=3.4 \mathrm{~mm}$ in the premixed flame and (b) $\mathrm{DFFO}=$ $3.0 \mathrm{~mm}$ in the counter-flow flame.

Figure 2. The hatched curve shows the lower and upper bounds of four separate PIE scans for the mass peak at $202 \mathrm{u}$ in the flame. The solid blue (gray in grayscale) curve displays the bounds for two PIE scans performed on pyrene. Also shown is the curve shape of the pyrene photoionization cross section $\left(\sigma_{\mathrm{PI}}\right)$ obtained from Verstraete et al. [36]. See text for details.

Figure 3. Relative concentrations of the most abundant species with mass $202 \mathrm{u}$ (left) and $226 \mathrm{u}$ (right) at a DFFO of $3.4 \mathrm{~mm}$ computed by SNAPS. These species account for $98 \%$ of all $202-\mathrm{u}$ species and $97 \%$ of all $226-\mathrm{u}$ species at $3.4 \mathrm{~mm}$.

Figure 4. Normalized signal intensities for the mass peaks at $202 \mathrm{u}, 226 \mathrm{u}, 266 \mathrm{u}$, and $278 \mathrm{u}$ as functions of the DFFO in the premixed flame. See the text for details.

Figure 5. SNAPS results showing the five most common pairs of radicals that combine to make structures at $266 \mathrm{u}$ and $278 \mathrm{u}$ at a DFFO of $3.4 \mathrm{~mm}$ in the premixed flame. These reactions account for $72 \%$ of all combined structures at $266 \mathrm{u}$ and $89 \%$ of all combined structures at $278 \mathrm{u}$. See text for details. 


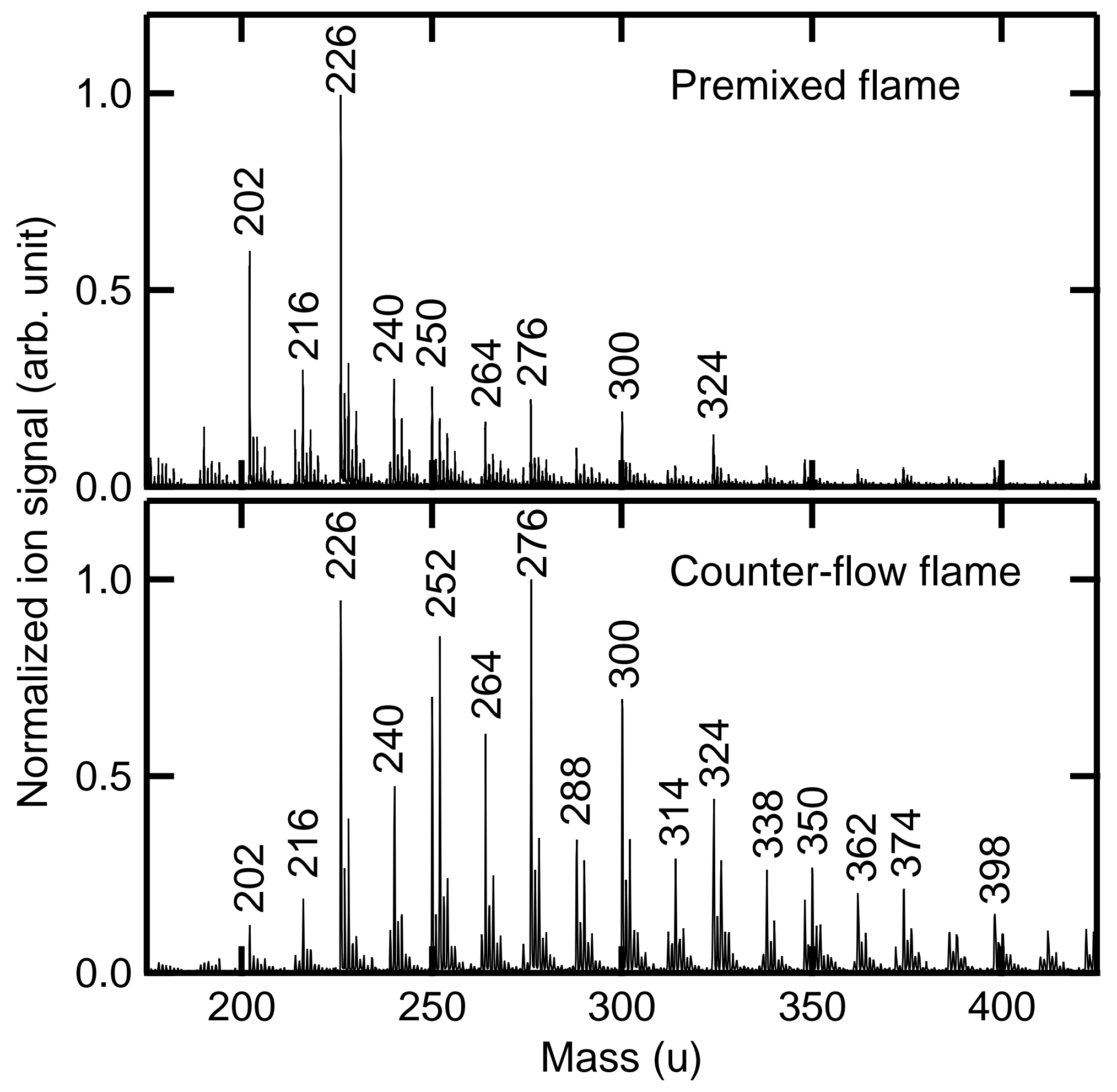




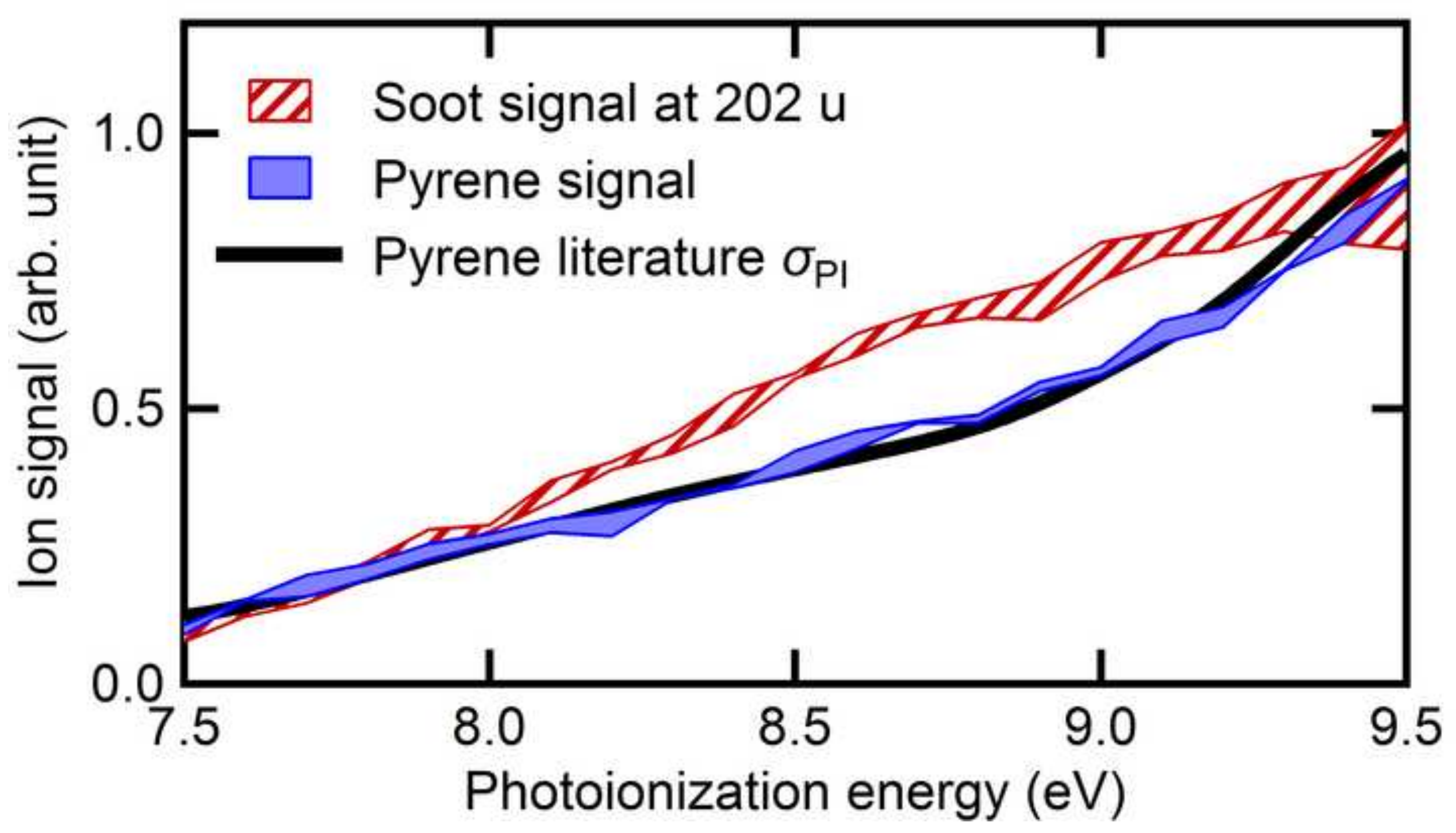


A.I $38 \%$

$202 \mathrm{u}$
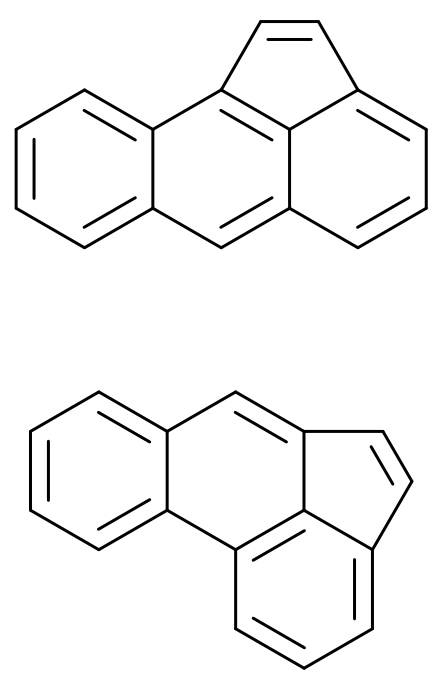

A.III $17 \%$

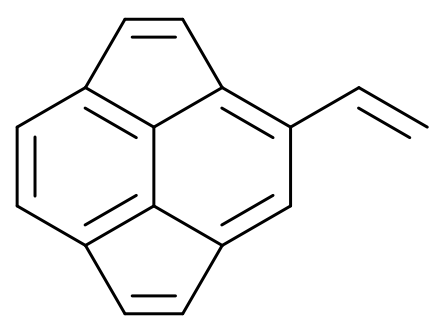

B.III 16\%

B.II 24\%

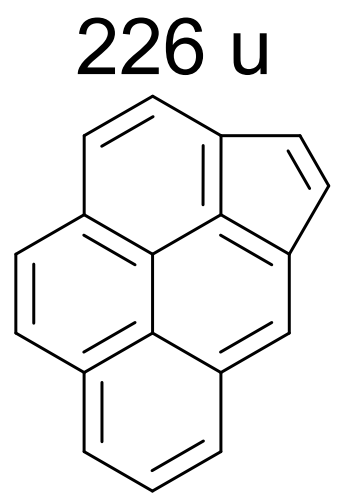

A.II $18 \%$

B.I $40 \%$
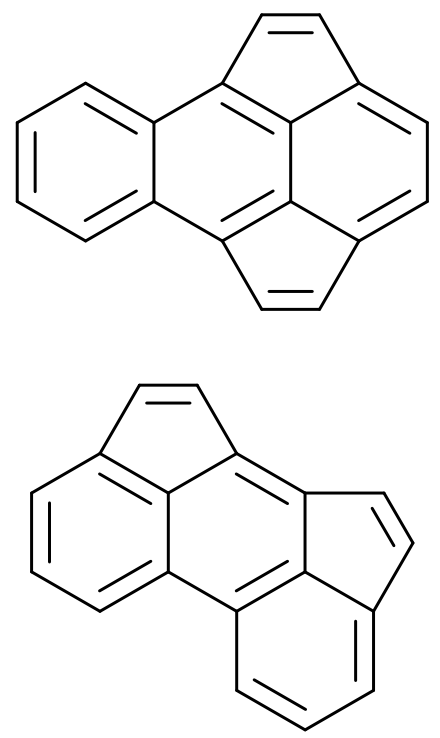

B.IV 12\%

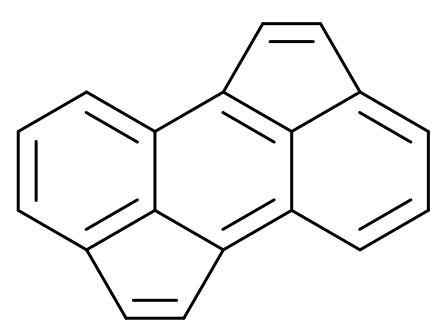

B.V $3 \%$

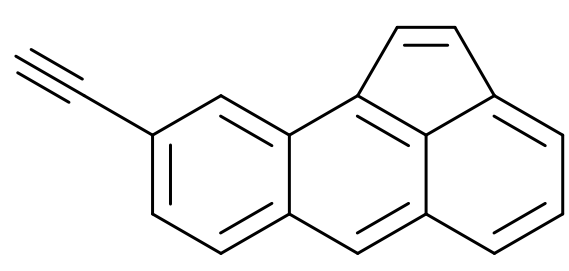

B.VI $2 \%$

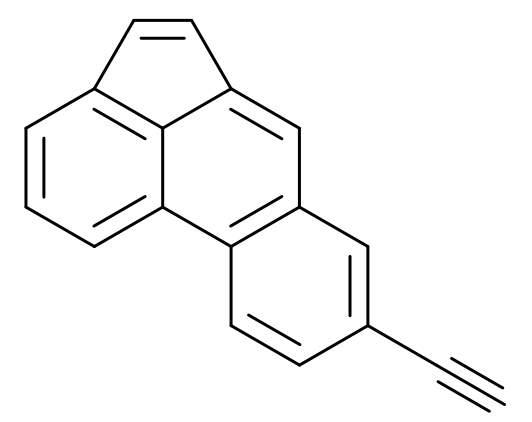




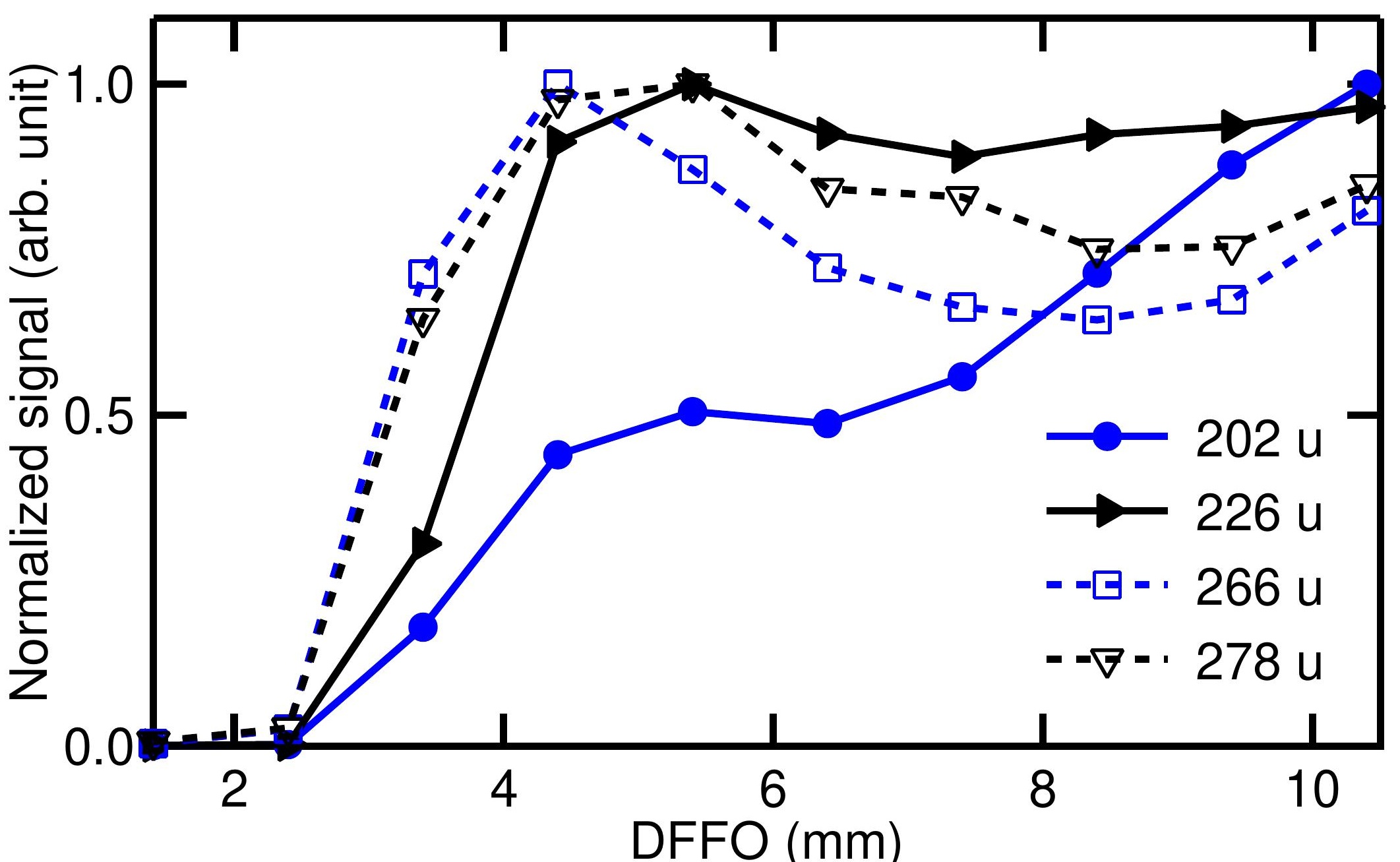




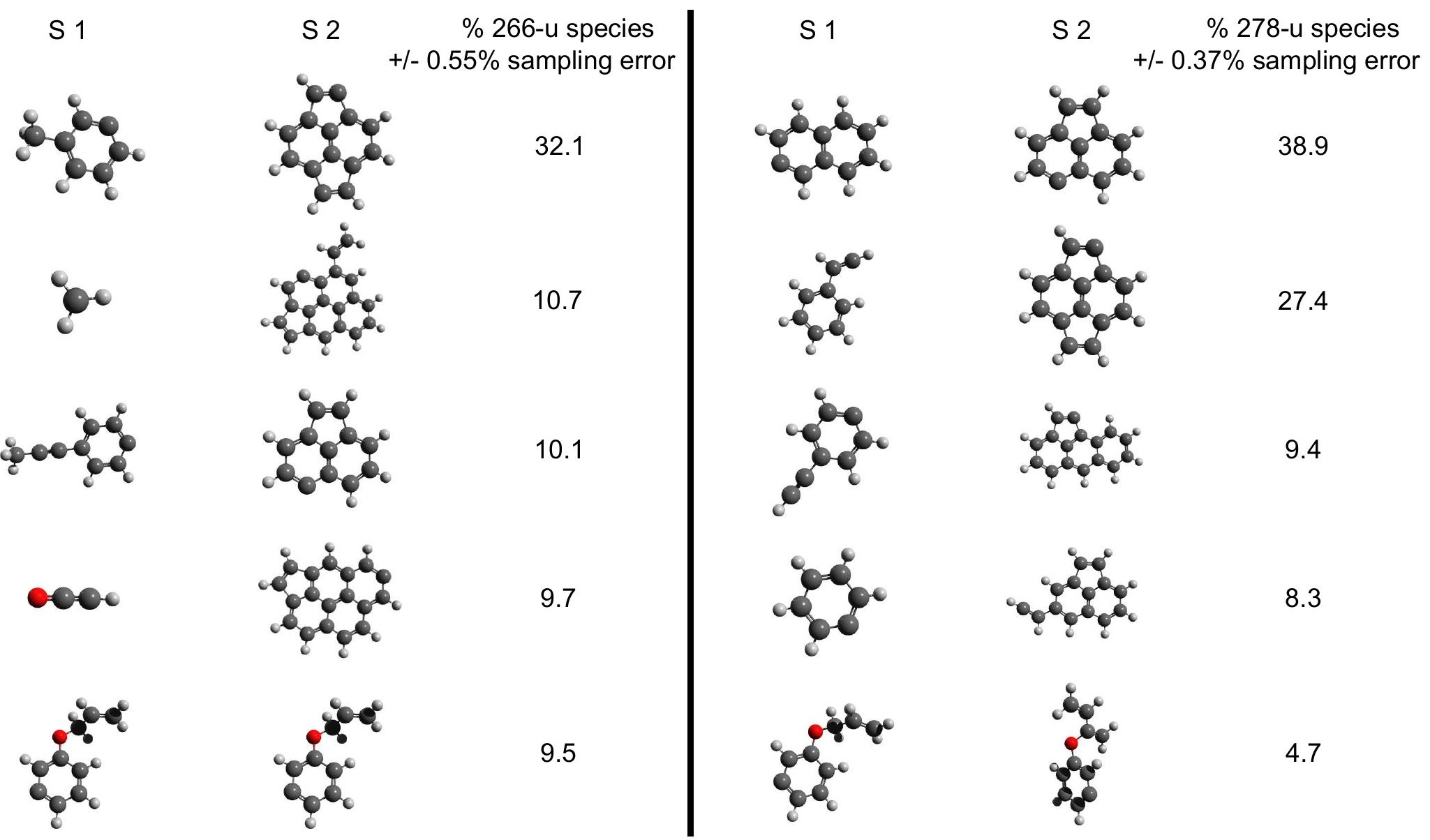

